\title{
Value of exercise testing in the assessment of the Fontan operation
}

\author{
Gunnar Norgård and Michael A. Gatzoulis
}

S INCE THE FIRST FONTAN OPERATION WAS DESCRIBED for tricuspid atresia, ${ }^{1}$ the technique has been modified to make it suitable for "correction" of complex heart malformations in which biventricular repair is not feasible. ${ }^{2,3}$ Maximal aerobic capacity in these patients improves after the Fontan operation, although still remaining subnormal in most of them. ${ }^{2.4-7}$ This is not surprising, since the Fontan circulation is dependent on passive filling of the pulmonary arteries, and is not infrequently associated with subnormal ventricular function. ${ }^{5,8}$

\section{Maximal exercise testing}

Maximal exercise testing has proven its worth in assessment of the hemodynamics and identification of determinants of cardiorespiratory function in patients after the Fontan operation. ${ }^{2,4-7}$ The main determinant for reduced cardiorespiratory function in these patients appears to be subnormal increase in cardiac output with exercise. ${ }^{5-8}$ This can be attributed mainly to reduced stroke volume, whereas the response of heart rate to exercise has been found to be near normal. ${ }^{5}$ Systolic function, when severely impaired, reduces cardiac output, but this is uncommon after the Fontan operation. Changes in preload and afterload also do not explain the low cardiac output as a response to exercise in these patients. ${ }^{5}$ Impaired diastolic, rather than systolic, left ventricular function in patients with heart failure, or subsequent to repair of tetralogy of Fallot, has been shown to limit exercise capacity. ${ }^{9,10}$ Diastolic abnormalities have been shown to be present both before and after the Fontan operation. ${ }^{11,12}$ These abnormalities probably become more pronounced during exercise. Our understanding of the complex cardiorespiratory interactions and determinants of cardiac output and pulmonary blood flow remains limited in the setting of the Fontan circulation. Presumably, respiratory fluctuations of the negative intrathoracic pressure, a skeletal-muscle pumping system and gravitational forces

Accepted for publication 31 January 1996 relative to caval venous flows contribute to forward pulmonary arterial flow. ${ }^{8}$

\section{Submaximal exercise testing}

Although maximal exercise testing has been of value in children after Fontan operations, the performance is dependent on motivation, and a true maximal test is seldom achieved in children. Submaximal testing is more relevant to daily activities, and accurate and reproducible measurements of gas exchange parameters can be obtained, independent of motivation. ${ }^{13-15}$ In addition, newer methods such as breath-by-breath gas analysis and mass spectometry allows the assessment of transient kinetics and evaluation of the initial phase of exercise. This might be important when guidelines for exercise are to be given, and also in the evaluation of different types of Fontan procedures. ${ }^{16,17}$ Gildein et al $^{16}$ found a reduced ability for short-term intensive activities in addition to reduced maximal aerobic capacity in patients subsequent to a Fontan procedure. Their recommendations on training involved an improvement of technical motor skills in order to perform these activities at less energy cost, rather than endurance or intensive training. In a recent study by Rosenthal et al, ${ }^{17}$ cardiorespiratory response to exercise differed between patients with atriopulmonary and total cavopulmonary connections. Patients with total cavopulmonary connections generated a smaller arteriovenous oxygen difference during exercise, which led the authors to suggest that this group was more likely to benefit from training.

The main merit of the study by Mertens et a ${ }^{18}$ published in this issue of Cardiology in the Young is the assessment of submaximal aerobic capacity and the elucidation of respiratory adaptation at submaximal exercise level. By using their extensive experience in cardiorespiratory testing in children, they give detailed information on ventilatory threshold and respiratory adaptation to exercise. Their finding of a reduced ventilatory threshold is in agreement with others. They suggest that the hyperventilation after Fontan operation is caused by a low ventilatory threshold. Moreover, 
decreased respiratory efficiency was found together with increased physiological dead space, thus suggesting important ventilation-perfusion mismatch. The small number of patients does not allow them presently to clarify the reasons for this mismatch. Their results are in keeping with others who demonstrated slight oxygen desaturation with exercise even in the absence of a previous Glenn shunt or drainage of the coronary sinus to the left atrium. ${ }^{4,6}$ This phenomenon of reduced effective ventilation could, however, be intrinsic to the Fontan circulation. Hypoperfusion of the lungs can give rise to pulmonary vascular disease in the upper lobes. As a consequence, ventilation-perfusion mismatch can occur between the upper and lower lobes. ${ }^{19}$

Hyperventilation and increased pulmonary blood flow were found to be more marked in patients with total cavopulmonary connections compared to those with atriopulmonary connections in the study by Rosenthal et al. ${ }^{17}$ These authors suggested that hyperventilation was a major drive increasing cardiac output by virtue of an increase in pulmonary blood flow. Since no difference in ventilatory threshold could be detected between the two Fontan groups, the hyperventilation cannot be explained by reduced ventilatory threshold alone. Although the studies of Mertens et $\mathrm{al}^{18}$ and Rosenthal et $\mathrm{al}^{17}$ differ in selection of patients, surgical procedures, and methods of testing, they both illustrate the complexity of cardiorespiratory function in patients following Fontan operations. Conclusions from single studies with small number of patients should be drawn with caution. The finding by Mertens et $\mathbf{a l}^{18}$ of a wide variety of submaximal performance, from just above resting metabolic level to the lower limit of normal, is in keeping with clinical experience, and of value as objective information. It remains to be seen whether minor changes detected during submaximal exercise will have any impact on late morbidity and mortality.

\section{Serial exercise testing}

The second part of the study by Mertens et al ${ }^{18}$ deals with serial testing of submaximal cardiorespiratory function. Despite its potential for early detection of changes in cardiorespiratory function, serial exercise testing is seldom used in children with congenital heart malformations. Nir et al ${ }^{4}$ performed a serial follow-up study 5.9 years (1.8-13 years) after a Fontan procedure using maximal exercise testing. Their most important finding was preservation of cardiorespiratory function with a slight reduction in oxygen saturation with time. Their patients, however, were highly selected, including only $3 \%$ of their Fontan population. Likewise, in the present study by Mertens et al, ${ }^{18}$ a second exercise test was performed in 12 of 18 patients (mean interval between the two tests 2.4 years). Some of the cardiorespiratory parameters could not be assessed in all patients. It is well known that the outcome after Fontan operation declines with time after the operation. In the excellent study by Fontan et al, ${ }^{20}$ decline in functional status and death increased with time of follow-up. A second hazard was experienced six years after surgery. The followup should, therefore, be longer before reliable conclusions can be drawn on preservation of cardiorespiratory function. With these limitations in mind, the findings by Mertens and his colleagues ${ }^{18}$ of preserved or slightly reduced ventilatory threshold, and preserved respiratory adaptation to submaximal exercise at mid-term follow-up, is of value. Only centers with vast experience in pediatric exercise testing, with well-validated methods, and capable of performing reproducible studies in healthy children and patients, can put forward new knowledge in this field and perform reliable serial exercise testing. ${ }^{5,15,21}$ It is, therefore, their responsibility to select patients carefully and perform longitudinal exercise testing as a routine part of follow-up in these challenging patients.

\section{Royal Brompton Hospital \\ Sydney Street, SW3 6NP \\ London, United Kingdom}

\section{References}

1. Fontan F, Baudet E. Surgical repair of tricuspid atresia. Thorax 1971; 26: 240-248.

2. Driscoll DJ, Danielson GK, Puga F, Schaff HV, Heise CT, Staats BA. Exercise tolerance and cardiorespiratory response to exercise after the Fontan operation for tricuspid atresia or functional single ventricle. J Am Coll Cardiol 1986; 7: 1087 1094.

3. de Leval M, Kilner P, Gewillig M, Bull C. Total cavopulmonary connection. A logical alternative to atriopulmonary connection of complex Fontan operations. J Thorac Cardiovasc Surg 1988; 96: 682-695.

4. Nir A, Driscoll DJ, Mottram CD, Offord KP, Puga FJ, Schaff HV, Danielson GK. Cardiorespiratory response to exercise after the Fontan operation: a serial study. J Am Coll Cardiol 1993; 22: 216-220.

5. Gewillig MH, Lundrstrøm UR, Bull C, Wyse RK, Deanfield $J E$. Exercise responses in patients with congenital heart disease after Fontan repair: patterns and determinants of performance. J Am Coll Cardiol 1990; 15: 1424-1432.

6. Rhodes J, Garfano RP, Bowman FO Jr, Grant GP, Bierman $F Z$, Gersony WM. Effects of right ventricular anatomy on the cardiopulmonary response to exercise. Implications for the Fontan procedure. Circulation 1990; 81: 1811-1817.

7. Cortes RGS, Satomi G, Yoshigi M, Momma K. Maximal Hemodynamic Response after the Fontan procedure: Doppler evaluation during the treadmill test. Pediatr Cardiol 1994; 15: 170-177.

8. Driscoll DJ. Cardiorespiratory responses to exercise after the Fontan operation. Circulation 1990; 81: 2016-2017.

9. Davies SW, Fussel AL, Jordan SL, Poole-Wilson PA, Lipkin DP. Abnormal diastolic filling patterns in chronic heart failure-relationship to exercise capacity. Eur Heart J 1992; 13: 749-757. 
10. Norgård G, Andersen K, Vik-Mo H. Echocardiographic assessment of left ventricular function at rest and during exercise in postoperative patients with tetralogy of Fallot. Cardiol Young 1994; 4: 267-276.

11. Akagi T, Benson LN, Williams WG, Freedom RM. The relation between ventricular hypertrophy and clinical outcome in patients with double inlet left ventricle after atrial to pulmonary anastomosis. Herz 1992; 4: 220-227.

12. Akagi T, Benson LN, Green M, Gilday DL, Freedom RM. Diastolic function pre and post Fontan's repair for univentricular connection. J Am Coll Cardiol 1991; 17: 34A. [Abstract]

13. Beaver WL, Wasserman K, Whipp BJ. A new method for detecting anaerobic threshold by gas exchange. J Appl Physiol 1986; 60: 220-227.

14. Sue DY, Wasserman K, Morrica RB, Casaburi R. Metabolic acidosis during exercise in patients with chronic obstructive pulmonary disease: use of th V-slope method for anaerobic threshold determination. Chest 1988; 94: 931-938.

15. Reybrouck T, Weymans M, Stijns H, Knops J, van der Hauwaert L. Ventilatory anaerobic threshold in healthy children. Eur J Appl Physiol 1985; 54: 278-284.

16. Gildein P, Mocellin R and Kaufmehl K. Oxygen uptake transient kinetics during constant-load exercise after opera- tions of ventricular septal defect, tetralogy of Fallot, transposition of the great arteries, or tricuspidal valve atresia. Am J Cardiol 1994; 74: 166-169.

17. Rosenthal M, Bush A, Deanfield J, Redington AN. Comparison of cardiopulmonary adaptation during exercise in children after the atriopulmonary and total cavopulmonary connection Fontan procedures. Circulation 1995; 91: 372-378.

18. Mertens L, Rogers R, Reybrouck T, Dumoulin M, Vanhees L, Gewillig M. Cardiopulmonary response to exercise after the Fontan operation. A cross-sectional and longitudinal evaluation. Cardiol Young 1996; 6: 136-142.

19. Matsushita T, Matsuda H, Ogawa M, Ohno K, Sano T, Nakano S, Shimazahi Y, Nakahara K, Arisawa J, Arisawa J, Kozuka T, Kawashima Y, Yabuuchi H. Assessment of the intrapulmonary ventilation-perfusion distribution after the Fontan procedure for complex cardiac anomalies: relation to pulmonary hemodynamics. J Am Coll Cardiol 1990; 15: 842-848.

20. Fontan F, Kirklin JW, Fernandez G, Costa F, Naftel DC, Tritto F, Blackstone EH. Outcome after a "perfect" Fontan operation. Circulation 1990; 81: 1520-1536.

21. Reybrouck T, Deroost F, van der Hauwaert LG. Evaluation of breath by breath measurements of respiratory gas exchange in pediatric exercise testing. Chest 1992; 102: 147-155. 